\title{
Realities of Participatory Community-Based Environmental Rehabilitation Projects: A Case Study of Soil Erosion Countermeasures in Western Kenya
}

Yuko Yamane, International Center for Agricultural Education (ICAE), Nagoya University, Nagoya, Japan.Email:yamane@,agr.nagoya-u.ac.jp

\begin{abstract}
This study attempts to describe the realities of participatory development projects in western Kenya, where severe soil degradation has occurred, using participatory observation methods. Six aid organizations administered development projects for environmental rehabilitation in the area; however, less than $10 \%$ of study area residents participated in project activities. This article argues that this lack of participation was fuelled by a disjuncture of understanding between aid organizations, community-based development organizations, and area residents about project purposes and goals. It suggests that in order for participatory development projects to be successful all stakeholders must understand and take ownership of the project. People who the aid organization called "community" often turned out to be a collection of unconnected people. In addition, not everyone who was involved participated out of a desire to stop soil erosion. Many people were not directly impacted by the gullies and their motivation for participation was purely for economic reasons. Thus, growing seedlings and planting them was seen more as a source of income than as a way to repair and restore the local environment. Such motivations need to be considered when creating participatory development projects
\end{abstract}

Keywords: participatory development, community development, environmental rehabilitation, Luo, Kenya

https://dx.doi.org/10.4314/jdcs.v6i1.5

(C) 2019. The Author. This work is licensed under the Creative Commons Attribution 4.0 International License (CC-By-NC-ND). Users may freely share and redistribute this work provided that the author and the Journal of Development and Communication Studies are fully acknowledged. Users may not tweak or remix and offer this work for sale. The full license may be accessed at https://creativecommons.org/licenses/by-nc-nd/4.0/

\section{Introduction}

The complex and dynamic nature of environmental problems requires flexible and transparent decision-making that embraces a diversity of knowledge and values. For this reason, stakeholder participation in environmental decision making has been increasingly sought and embedded into national and international policy (Reed, 2008). Since the 1990s, participatory development has become an important strategy in the creation of community-based development projects in rural areas of the Global South. This concept is not a superficial notion designed to make rural people assist with 
development projects; it is a principle based upon the idea that activities must promote human-centred development, be respectful of the independence of individuals, and allow people to improve their own situations (Ohama, 2007). Many environmental rehabilitation projects conducted by both governmental agencies and nongovernmental organizations (NGOs) have adopted the phrase "participatory development" or "community-based development" in their project name or methods. However, participation in such efforts varies and sometimes the local community members' connection to these projects is little more than ephemeral in nature (Saito, 2002).

This article explores this issue. It does so by detailing the work of aid agencies in western Kenya to combat soil erosion among communities near Lake Victoria and how they engaged community members in that work. This article asks: Do community members and aid agencies understand participation, or even community, in the same way? It also considers what that means for the idea of participation if they do not.

\section{Participatory Development}

Development projects have sometimes been criticized for taking a top down approach to development (Escobar, 201). Interventionist approaches to development have created what Quarles van Ufford, Giri, and Mosse (2003) call disjunctures - such disjunctures can happen at any stage and at any moment in a development project, but breakdowns in understandings between project leaders and the communities they serve should be a major concern to those engaged in development work. Such disjunctures can lead to project failures as there is often no shared understanding of project goals (Quarles van Ufford, Giri, and Mosse, 2003). Because of this, there has been a growing interest in the creation of participatory or community-driven development projects. The drive to bring the community into development projects has also gone hand-in-hand with the rise in development projects seeking to take advantage of new communication technologies (Fair and Shah, 1997), although Mohan and Stokke (2000) would caution researchers and aid agencies against uncritically embracing ideas about what constitutes "the local" - what we call community in this article - in such projects.

Efforts based upon a participatory model appear to offer all project stakeholders a voice and a choice. However, community-driven development, participatory planning, and similar initiatives which make claims of "full participation" and "empowerment" can turn out to be driven by particular gendered interests, leaving the least powerful without a voice or much in the way of choice (Cornwall, 2003). As pointed out by Mohan and Stokke (2000), ideas about what is "local" can also be driven by political forces that can sometimes be far removed from the realities of the localities they plan on working with. The localities this paper examines are located in western Kenya. 


\section{Combating Community Erosion}

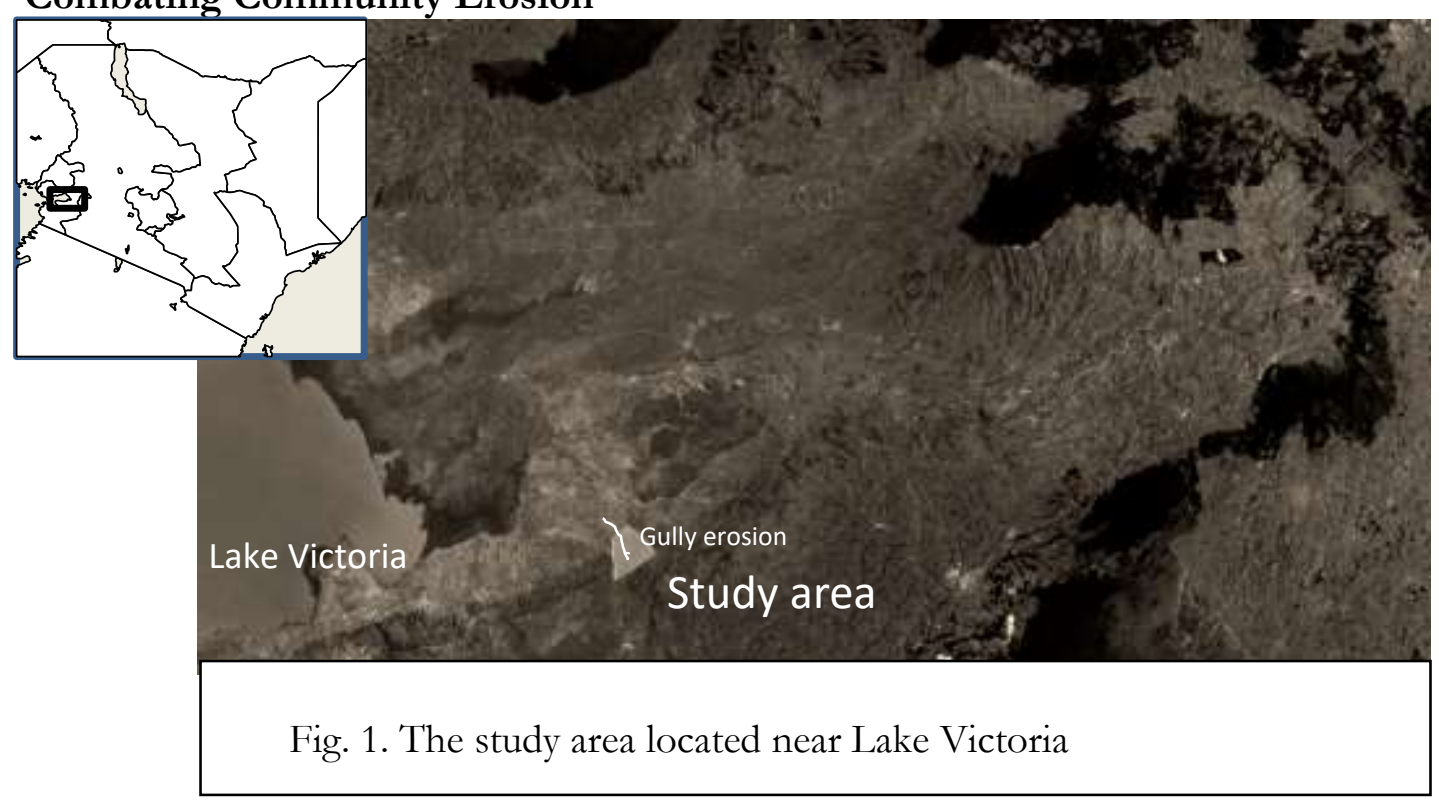

On the north-eastern side of Lake Victoria at an altitude of about 1,000 m, vast plains expand over the land (Fig. 1). Three sides of this plain are surrounded by the Rift Valley; more than 2,000 meters above sea level (MASL) at the top of the Rift Valley lies a plateau. The Nyando River runs from the highlands of the Nyando Province at 2,000 MASL to Lake Victoria at 1,184 MASL. About 450 to 500 years ago, the Luo, a Nilotic people, emigrated from Sudan to the north coast of Lake Victoria, including the Nyando River Basin (Shipton, 2007). Throughout the basin, the Luo engaged in mixed farming, including crop cultivation and animal husbandry (World Agroforestry Centre, 2006). The area is characterised by very high population densities of 214 people $/ \mathrm{km}^{2}$ on average, with over 1,200 people $/ \mathrm{km}^{2}$ in some areas of the basin (Njuguna, 2004).

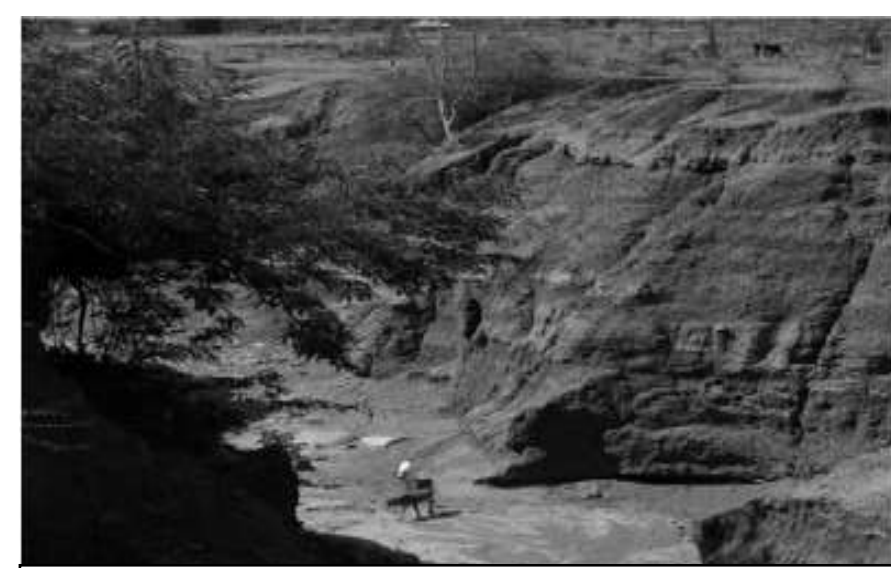

Fig. 2. Gully heads expanded in the north eastern part of the study area with more than $20 \mathrm{~m}$ depth

The study area is located in the middle of a slope. Hence, severe soil erosion has been aggravated by flash floods from the plateau. The study area $\left(0.18-0.19^{\circ} \mathrm{S}\right.$, $\left.34.59-35.23^{\circ} \mathrm{E}\right)$, the Jimo East sublocation in the Nyando subcounty, is elevated at $1,100-1,300$ MASL. In this sublocation, several gullies have been formed, with the longest one stretching over 10 $\mathrm{km}$ and the deepest gully exceeding $20 \mathrm{~m}$ in depth (Fig. 2). The area faces the border of the Rift Valley Province, in which most people are Kipsigis engaged in intensive farming, including tea cultivation (Nyasimi et al., 2007). The Kipsigis' land near the border is used extensively, and some land is rented by the Luo people for grazing and farming. The Luo people have a virilocal patriarchal society with a high rate of polygamy (Shiino, 2008). Their minimum residential unit, called a dala, consists of a man, his multiple wives, their children, and their grandchildren (Shiino, 2008). Each Luo village is formed as an aggregation of dalas occupied by people who believe they share a specific ancestry 
(Shiino, 2008). In addition to kinship, in the Luo society, there are several customs regarding social responsibility and reciprocity. For example, widows are cared for and marriage is confirmed through the exchange of livestock - a practice that is commonly carried out by Kenyan pastoralists (Konaka, 2006).

Annual rainfall around Lake Victoria reaches more than 1,300 mm per year (Fig. 1); contrastingly, more than half of the total area in Kenya is arid with less than $700 \mathrm{~mm}$ of annual rainfall. However, the area faces other difficulties. In the Nyando district where the study area is located, $66 \%$ of people are classified as living below the absolute poverty line and experience various problems such as low crop production, human disease (especially HIV/AIDS), lack of clean water, and livestock disease among other issues (Brent, 2005). In addition, severe soil degradation has become a serious problem in this district, especially in the study area (Hoshino et al., 2004; Sigunga, Hoshino, Onyango, Asanuma, and Kimura, 2011; World Agroforestry Centre, 2006). Because the region's residents suffer from severe soil erosion and high levels of poverty, multiple aid organizations have launched environmental rehabilitation projects there.

This article examines several projects in order to understand where participatory development goes right and what misunderstandings can lead to it going wrong. It considers how aid workers conceptualized the idea of community as they worked to improve the environment in the area. This article also aims to convey the realities of the environmental rehabilitation projects from the local people's perspective as well as how they participated in the project. As this discussion will make clear, there were many moments of disjuncture as the development projects worked to combat soil erosion; during the discussion we consider how (mis)understandings of community may have fuelled these disjunctures.

\section{Research Methods}

In order to understand the work of aid agencies as well as the reaction of the

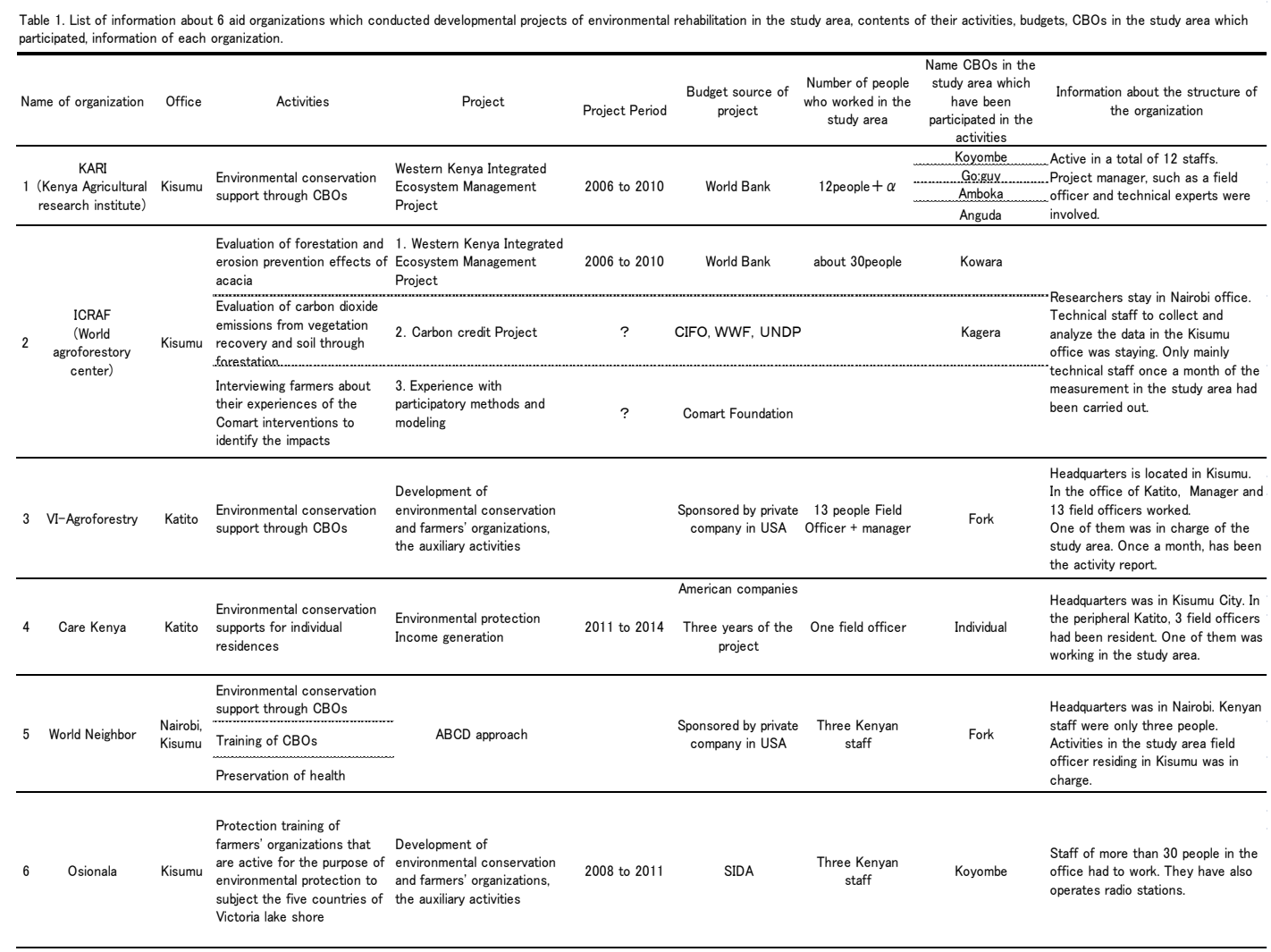

communities with whom they worked, a mixed method approach was taken in this 
project. The first of these methods was participatory observation, a method which is popular in anthropological studies (Maxwell, 2005). To facilitate this aspect of the research, the first author stayed with a host family in the study area for a period of 12 months over the course of several years (that is, March-May 2009; January-March and October 2010; February, July, and December 2011; May 2012; and January 2013). During the stay, the author conducted a number of surveys and observed the ordinary lives and relationships of local residents. The information and data collected mainly between January-March 2010 and February 2011 were used in this study and included participatory observation of aid organizations, surveys of members of the communitybased organizations (CBOs) who worked with those organizations, and interviews with officers who work for the aid agencies. In order to conduct the participant observation portion of this project, the author identified six aid organizations that had conducted environmental rehabilitation development activities in the area (Table 1); information pertaining to 11 specific activities was also collected (Table 2). In seven cases, the author participated in seminars or meetings to authenticate organizational activities and record comments from members of the CBOs and officers of the aid organizations.

Surveys of $\mathrm{CBO}$ members consisted of two separate investigations. In the first, during February and March 2010, the author visited the leaders of the CBOs who participated in the Kenya Agricultural Research Institute's (KARI's) project and asked about their activities and member details. In the second, which took place February and July 2011, individual visits were made to the homes of nearly 59 CBO members. During these visits semi-structured interviews were carried out using a questionnaire. Members were asked questions about their motivation to participate in the activities of the CBOs. The questionnaire also covered details of the CBO's activities and status, as well as an evaluation of the KARI project.

Interviews with officers in the aid organizations, the third prong of this study, were completed from January to March 2010. The author visited the offices of those that had participated in projects conducted in the study area. The goal of these interviews was to investigate the purpose and content of the projects as well as the budget and resources set aside for them.

What follows is a discussion of the findings of these investigations. It examines the ways aid agencies conceptualized their projects and the communities they worked with, the response of those communities to the projects, and how individuals responded to project goals. It considers what misunderstandings and disjunctures emerged, how they might have been avoided, before asking what we can do to ensure there is true local participation in participatory development projects.

\section{Findings}

\section{How Aid Agencies Understand Development Projects}

As mentioned, six aid organizations conducted projects in the study area (Table 1) in 2010 during the author's stay: the Kenya governmental research institute known as KARI, the international agricultural research institute known as the World Agroforestry Centre (hereafter, ICRAF), and multiple international and domestic NGOs. Most of the organizations' projects were focused on environmental rehabilitation and involved working with CBOs that were identified by letters; for example, one of the groups involved in raising chickens was identified as Group A while a CBO which was focused on planting trees was identified as Group K. Table 2 shows the days and details of development activities performed by the aid agencies interacting with the CBOs. For a total of 20 out of 67 days and about once every 10 days, it was observed that aid organizations visited the study area. 
Information was collected from seven of these activities, referred to below as cases. Among them, Case 7 - KARI's meeting - was the primary focus. Remarks made by attendants during the meetings were recorded.

Case 1: Seminar of asset-based community development ( $A B C D)$ approach in Kisumu Hotel on January 26-30, 2010 (language: English).

For five days from the $26^{\text {th }}$ to the $30^{\text {th }}$ of January, a seminar was hosted by the

Table 2. Activities and dates for support organizations in the study area (Survey period : 14th Jan to 20th Mar 2010).

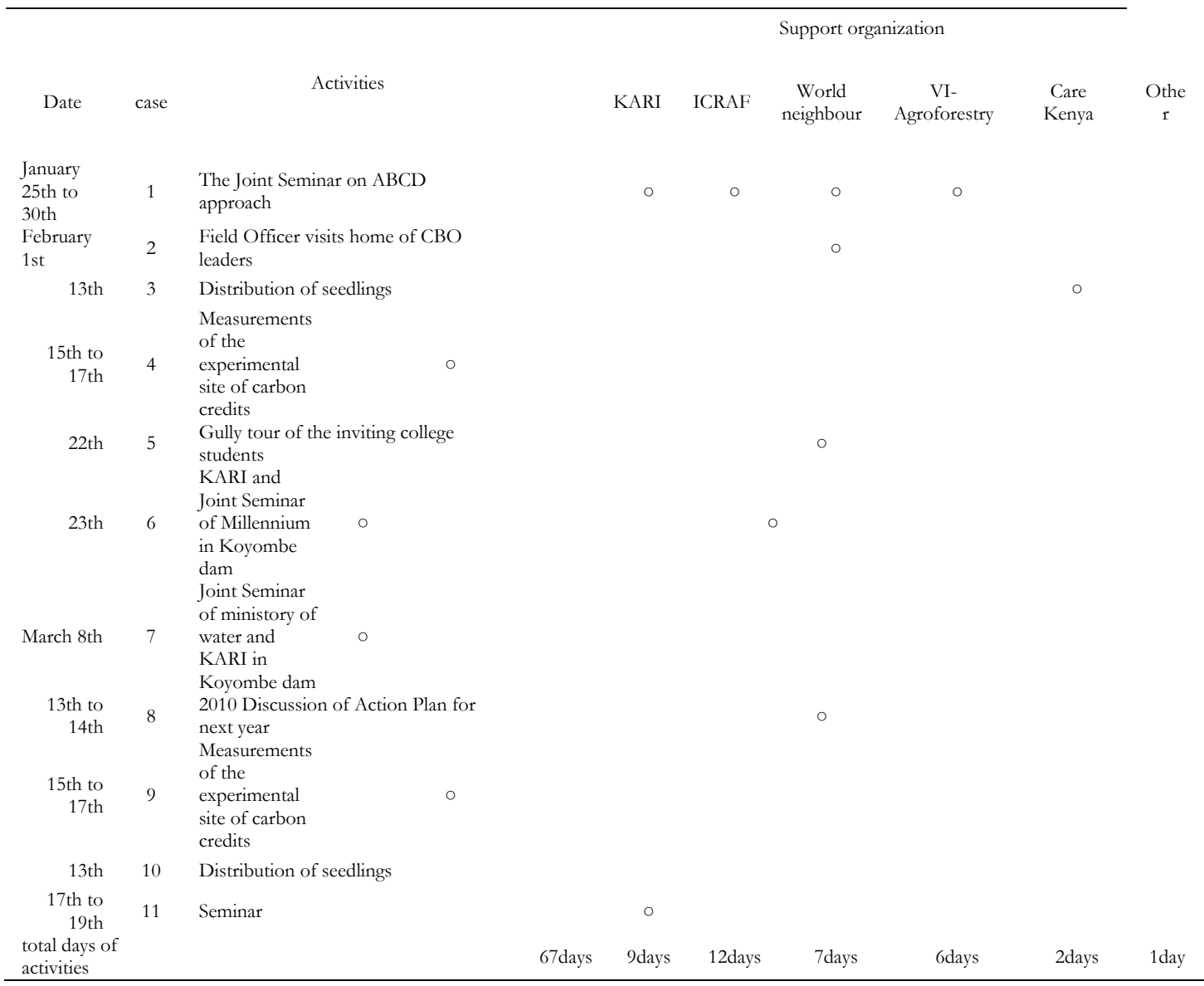

NGO "World Neighbours." Officers from ICRAF and KARI, three Kenyan staff members of the NGO, and a Canadian researcher from St. Francis Xavier University attended this seminar. Also, in attendance were farmers from Ethiopia, members of the $\mathrm{CBO}$ of the Kipsigis people living in the target area of the project, and three $\mathrm{CBO}$ members from the Luo people who participated in KARI's project. On the first day, they walked around the study area and observed dairy goats kept by a member of a CBO named $F$ group. Two sites of tree nurseries from the J group and the $\mathrm{K}$ group, which were part of KARI's project, were also observed. They then visited the gully heads where severe gullies with a depth of $20 \mathrm{~m}$ and a length of $14 \mathrm{~km}$ were observed. Members of the $\mathrm{CBOs}$ explained the situation regarding the expansion of the gullies and their attempts to prevent them.

On the second day, they moved on to the Kisumu Hotel in Kisumu city. The Canadian researcher gave a lecture on the Asset Based Community Development 
(ABCD) approach and discussions were held by all participants in the meeting room throughout the day (9:00 a.m. to 3:00 p.m.). Representatives from each CBO attended the seminar. The main theme of the discussion was how to solve village problems through the independent use of local assets. The lectures and subsequent discussions were conducted in English.

Case 4: Measurements of carbon dioxide emissions from the soil in the carbon credit project during February 15-17.

In this case, measurements were taken for carbon dioxide emissions from surface soils in the carbon credit project. Six technical staff members from the ICRAF led the investigation. The measurements were recorded from two types of vegetative sites. In one site, acacia trees had been planted to test the effect of forestation in preventing sheet erosion. The trees were planted about four years before when the projects (supported by the World Bank) began and had already grown about $4 \mathrm{~m}$ tall. Other sites included control sites without forestation, wherein bare soil was observed. Measurements to clarify whether vegetative conditions affected carbon dioxide emissions from the soil were taken once per month.

Case 7: Achievements report meeting for the project funded by the World Bank for KARI on March 8, 2010 (language: Swahili).

KARI had been running a World Bank-funded project in the area since 2005. In this meeting, representatives of the CBOs who participated in the project discussed their achievements and evaluated the project, which was to be finished in June 2010. They also reported the status of their activities. More than $10 \mathrm{CBO}$ representatives who participated in the project spoke in front of KARI officers and officers from the Ministry of Water who were planning a new project for the area. Representatives from the $G$ group, K group, and A group (from the study area) and other CBOs, for example, the Kipsigis people, also attended the meeting.

Case 8: Seminar of World Neighbours on budget requests by CBOs for next year, March 12-13, 2010 (language: Swabili).

A field officer and representatives from 15 CBOs in the study area and other areas attended this seminar. In the seminar, the activity plans and expected expenses for the next fiscal year were presented by 24 people from various CBOs. Apart from vegetable gardening, tree nursery management, and bee keeping, activities included counselling for persons suffering from AIDS. The budgets compiled by the $15 \mathrm{CBOs}$ amounted to nearly 30,000 USD.

Case 12: Seminar of World Neighbours for discussion on a proposal for the budget from GTZ, February 18, 2011 (language: Swabili).

In this seminar, a field officer announced a budget supplied by the German Agency for Technical Cooperation (GTZ). Members of the CBOs were advised to apply for funding by submitting detailed project proposals. The purpose of the seminar was to gather consensus to submit proposals to GTZ. The seminar was performed at the church located near the centre of the village and the CBOs who participated were mostly the same as in Case 7: F group, A group, $N$ group, $K$ group, and $G$ group. With the exception of the F group, the same CBOs had participated in the KARI project the previous year. Representatives who participated reported the activities of their organizations. 


\section{Realities of Seminars}

Among the abovementioned cases, the KARI seminars of Case 7 were the primary focus of this study. During the seminar, the author recorded remarks made by members of the CBOs and officers of the aid organizations. The author wanted to verify how representatives of the CBOs and officers evaluated the project. As such, they discussed their achievements and evaluations of the project, which was to be finished in June 2010. The status of their activities was also reported, including estimating the takeover of projects. The recorded remarks of the speakers are presented verbatim without editing.

Speaker 1, J group: We plan to make a dam to control water flows. As for us, we examined approximately five dams and hope that you support it financially. In addition, we maintain tree nurseries and build dams. We do activity of tree nursery and activity of making dam. An NGO will support it. We work with World Vision (name of NGO) and I hope we can increase goats for milk.

Speaker 2, A group: The activity of the poultry farming that KARI supported still goes well. The activity such as other services of loaning and horticulture or tree nursery goes well, too. We have 20 members and doing activities. Our group work with the NGO called the World Neighbours. I thank you for activity of KARI. We have been frightened by the fear of the gully very much before knowing tree nursery and did it for a long time, but now we became able to live safely because we learned to prevent expansion of gully by planting a tree now. We cannot observe gully in our fields. We intend to continue being active as it is.

Speaker 3, S group: S group should thank you for KARI. My name is J, G (showed only initials), the Secretary (title of the group) of our group. We got budget of 120,000 Kenya schilling for activity of bee keeping and Tree nursery. We made facilities of bee keeping with this money. In addition, I did Tree nursery and planted a tree. KARI gave us seeds and told us to plant trees. We have not come to yet harvest honey, but I think that we can do it. The present main activity is bee keeping.

Speaker 4, G group: You told us that we must plant trees. I'm grateful for that. We planted a lot of trees, and a lot of trees grew. We pull water supply before and was able to plant a tree, but water is in state that there is not it now afterwards without being able to pay water supply charges. The tree has died by result without water, too. You brought tomato and eggplant and we planted them, but there were not water and have died. Profit disappeared really after water disappeared. All participants said environment is improved, but I cannot agree at all. I live very near the gullies. The gullies will take my house sometime soon. We planted trees near the gully, but when rain fallen, and the soil collapsed, and all have disappeared. In other areas, damage of the serious gully was observed at the place called Kolwe. However, an expert comes and puts stones and they 
knew the example that prevented a gully. The gullies might stop if I do such preventive measures, but the gully in this area still continues.

Speaker 5, Mr. S (group unknown): I started activity in 2007. I think that KARI helps us very much. But it is very difficult to stop gullies. But we must continue making an effort. If everybody cooperates, it can surely alleviate the problem.

Speaker 6, O group: We do activity such as Tree nursery, bee keeping, horticulture, soil conservation, goat for the milk, rehabilitation of gullies, care activities for people of HIV positive. We knew that cash income was provided by planting the seedling of the tree.

Many speakers only mentioned their activities and the situation of their own CBOs. The female leader of the poultry group mentioned that activities were going well and made very positive remarks regarding the results of that project. Of the six representatives of the CBOs, only Speaker 4 gave critical remarks on the results of the project. He complained that erosion continued to expand. He also said that tree nurseries and forestation around the gullies had not become a fundamental solution. Although two people, including Speaker 4, had criticised the project, their remarks did not concern the other attendants. At the close of the meeting, the participants were generally satisfied.

However, while awaiting the officers' arrivals prior to the meeting for Case 7, members of the CBOs openly complained about the project saying such things as "People who went to the trainings were worthless," and "Projects should choose people who really suffer from gullies to go to training." One of them said that KARI officers should hear these problems in order to deal with them. However, nobody made such remarks during meetings with the officer except Speaker 4, suggesting that what reality was in regards to these projects for $\mathrm{CBO}$ members was different than what they presented to the agencies funding the projects.

In addition, the author had performed an interview with the poultry group leader before the meeting. In this interview, she said that they had not received any benefits from poultry activities: "Chickens die easily, but we must feed them every day because the officer sometimes comes to visit." For this reason, she said, she had to continue the activities of the poultry project, not because she felt she was benefiting from it. However, during the seminar she thanked the officers of KARI and did not mention what she saw as the lack of benefit to the community. She also mentioned that they had not observed any soil erosion in their cultivation fields after the reforestation.

In Case 1 and Case 6, representatives of the CBOs mentioned the problems of daily life, gullies, or the current situation of the CBOs. However, few people touched on specific group activities that could improve the situation. Many of them said that aid organization-supported activities were continuing successfully. In contrast, aid organizations did not provide the means and opportunities to objectively evaluate the real achievements. As a result, problems were reported only by representatives of the $\mathrm{CBOs}$ at the seminars. In all of the seminars and meetings, the representatives of the CBOs continued to make very superficial remarks.

\section{Understanding Aid Organizations}

Four NGOs also carried out projects in the study area at this time. Three of them are categorised as international NGOs sponsored by companies in the United States, while one was categorised as a domestic NGO. A common characteristic of these NGOs was that only people who were called field officers were visiting the target areas. An international NGO - Care Kenya - has a large office in Kisumu city with many Kenyan 
officers. However, support activities that had been conducted in the study area were carried out by only one field officer living in Katito Town, a neighbouring village in the study area. For the duration of the project, she conducted activities like providing tree seedlings and horticultural crops directly to the local people without going through the CBOs. She also gave training sessions in order to teach cultivation methods. She updated her activity diary every time she visited the project area in order to compile a detailed progress report.

VI-Agroforestry is also an international NGO with offices in Katito Town. Thirteen people referred to as field officers were working in this office. Their main responsibility was to provide tree seeds to be planted in their respective areas of responsibility, which fulfilled their requirements according to the CBO. Furthermore, all interaction with farmers was carried out in the office. Although the field officer had frequently come to see $\mathrm{CBO}$ representatives in the study area, activities observed by the author only included field visits to the gully heads by university students. Field officers had attended other seminars that World Neighbours - one of the international NGOs - had sponsored.

World Neighbours had only three Kenyan staff members at the time of investigation. Only the field officers stayed and participated in activities in the study area. They did not have their own office in Kisumu city; the field officer had a room in the office of ICRAF located in Kisumu city. Their main activity was holding seminars in the target area.

Osionara is a domestic NGO that has a large office on the Lake Victoria shore. Around 50 Kenyan staff members were working in their office and they have even opened radio stations. This NGO tried to write a proposal and receive funding from various agencies. Three people from this NGO contributed to the project to support the activities of CBOs in the Lake Victoria shore area, including a $\mathrm{CBO}$ in the study area. Only the field officer had visited the study area to check on the CBOs' activities attempting to prevent soil erosion once a year.

The author also visited KARI's office and carried out interviews to gather information about the contents of the project and structure of their organization. The author asked questions to project managers about the project's purpose and how the actual operation was managed. The project manager explained that their project had been carried out by 12 KARI staff members who had set up an office in Kisumu city. He briefly explained the project proposal and outlined the methods. He is a Luo, and he seemed proud that the project could be done in a village of compatriots. According to the final report submitted to the World Bank in 2010, the project development objective was to improve the productivity and sustainability of land use systems in selected watersheds in the Nzoia, Yala, and Nyando river basins through the adoption of an integrated ecosystem management approach (World Bank, 2010). When the author visited the field officer for an interview in 2010, he had already been transferred to another department located on the border of the province. He said that transferring staff to other departments for a short-term assignment is common, thus making it difficult for one person to remain involved in the project consistently. In addition, he said that because KARI is a government organization, they have limitations in how they use their budget. The relationship between the CBOs and KARI was very complex, because operations were run by different field officers and by multiple professional engineers. It became apparent that it was difficult to know who had been involved in what activities at any point in time. 


\section{Community-Project Disconnect}

In order to better understand the work of aid organizations in the study area, the author attended a number of their activities. It was discovered that most of the activities were seminars and meetings. As already mentioned, CBO representatives' remarks in these meetings were superficial regarding the success of their projects or activities. Most of them did not mention the problems they faced nor did they request more resources or funding from aid agencies in order to improve project conditions. Furthermore, aid organizations did not track the everyday activities of the CBOs. There was a disconnect between the goals of the aid agencies and what was happening on the ground in the communities served by the CBOs.

KARI was the largest project for the purpose of environmental rehabilitation in the study area from 2005 to 2010 . Four CBOs had participated in the KARI project in the study area. In 2010, the author visited the homes of the leaders of each CBO and asked for member names. In 2011, a semi-structured survey was carried out using a questionnaire for each member. 59 individuals participated in the survey, these were almost all of the members of the four CBOs whose names were given by their leaders.

Members of the four CBOs consisted of people who were 20-70 years old with $86 \%$ of them being female (Fig. 3 a, b). Additionally, about one-third of the members had stopped participating in CBO activities and one-third had left the group in 2011 (Fig. 4). The only members who had remained involved were four people from the A group and 16 people from the K group. Less than one year after the end of the KARI project, two-thirds of the participating members had abandoned or discontinued their activities.

(People)

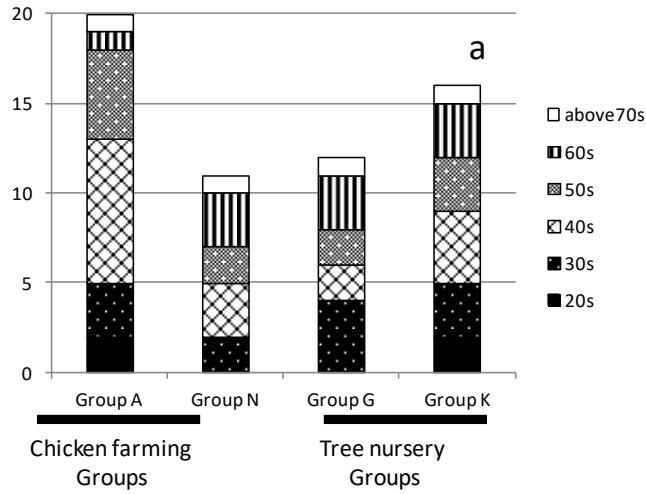

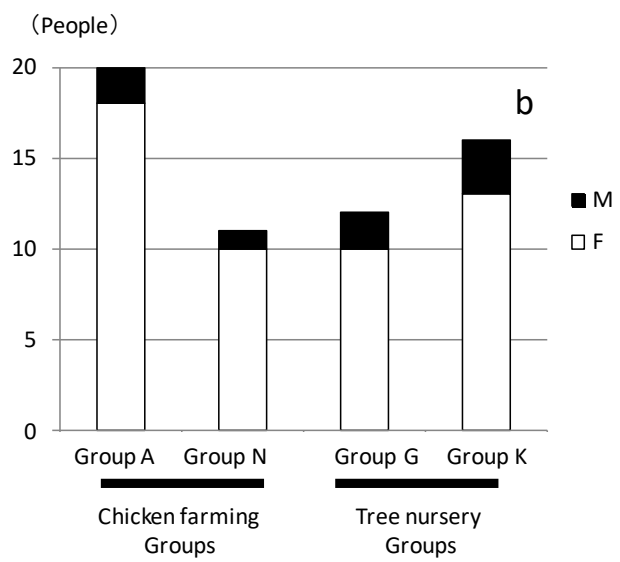

Fig. 3. Age and sex of members of four CBOs which participated in KARI's project (2011). 


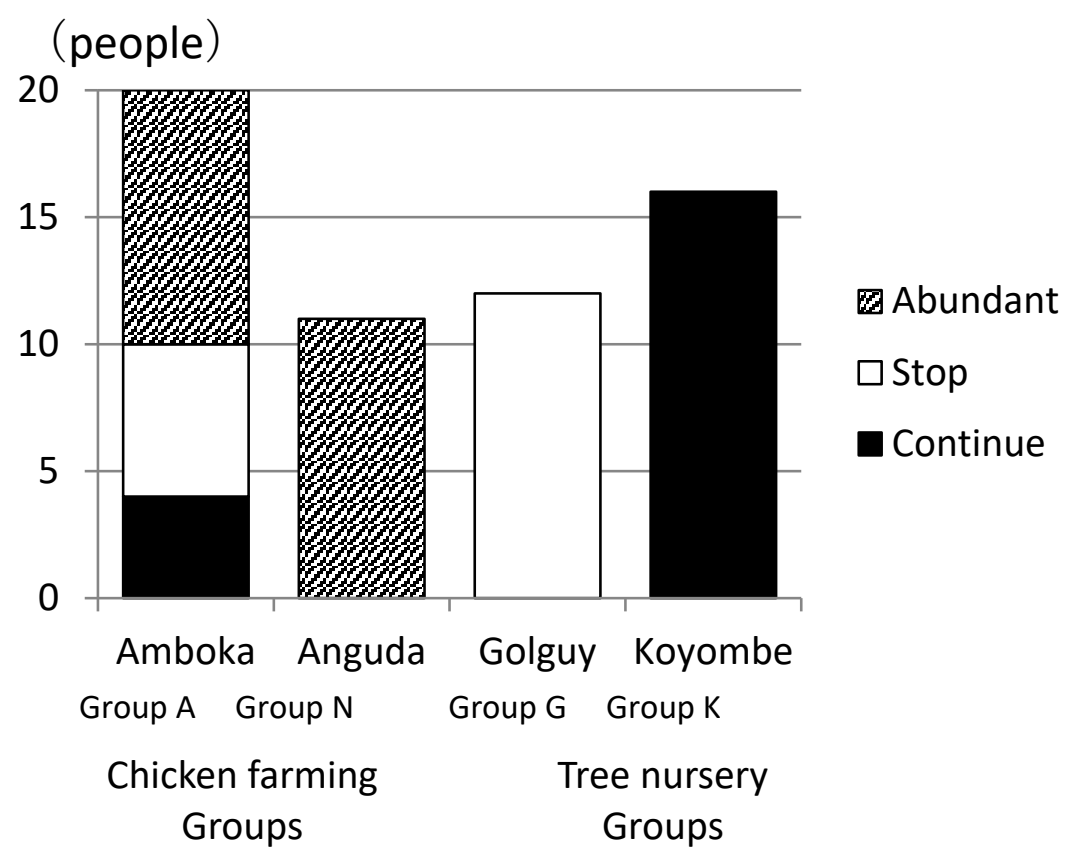

Fig. 4. Activity situations in 2011 of the people who have been members of CBO (2011).

To understand why so many members discontinued their activities, their motivations to participate and their assessments of the project were recorded. Results showed that about half of the members (30) were motivated to participate in order to receive compensation in the form of goods and money or food (Fig. 5). Of the people who were interested in the activity itself, one-third (22) wanted to participate in the development project, were invited by neighbours, or were interested in the specific activity such as the creation of a tree nursery. Only seven people participated to prevent the expansion of erosion. One of them was from the $\mathrm{K}$ group and six of them were from the $G$ group. These results show that very few people shared the goal of rehabilitating environmental conditions or that that they understood that the project's aim was to stop soil erosion.

The evaluation of the KARI project showed a large division within groups and between groups (Fig. 6). A total of 27 people made negative or strongly negative evaluations. On the other hand, 24 people made positive evaluations. Two people claimed that they did not know about the project, three people did not know about KARI, and two people answered they did not participate in the project; these seven people did not even know that they were participants in the project even though their names had been provided by the leaders of the CBOs.

When

asked the reason for their answers in the evaluations, it was found that if participants felt they could receive something, they gave positive evaluations. On the other hand, if

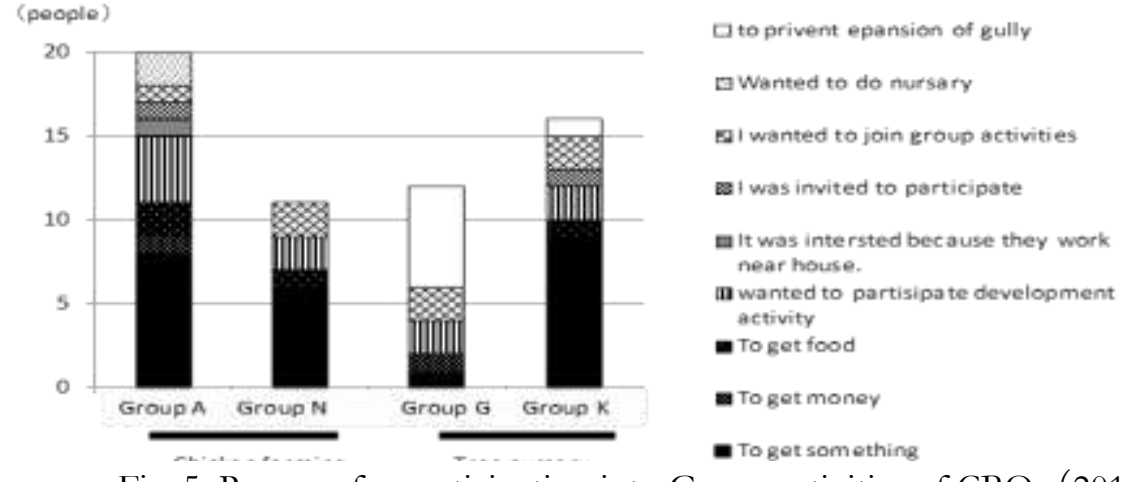

Fig. 5. Reasons for participation into Group activities of CBO (2011) 
they felt unfulfilled, they gave negative evaluations. Interestingly, seven people who participated out of a concern for soil erosion gave negative evaluations of the project.

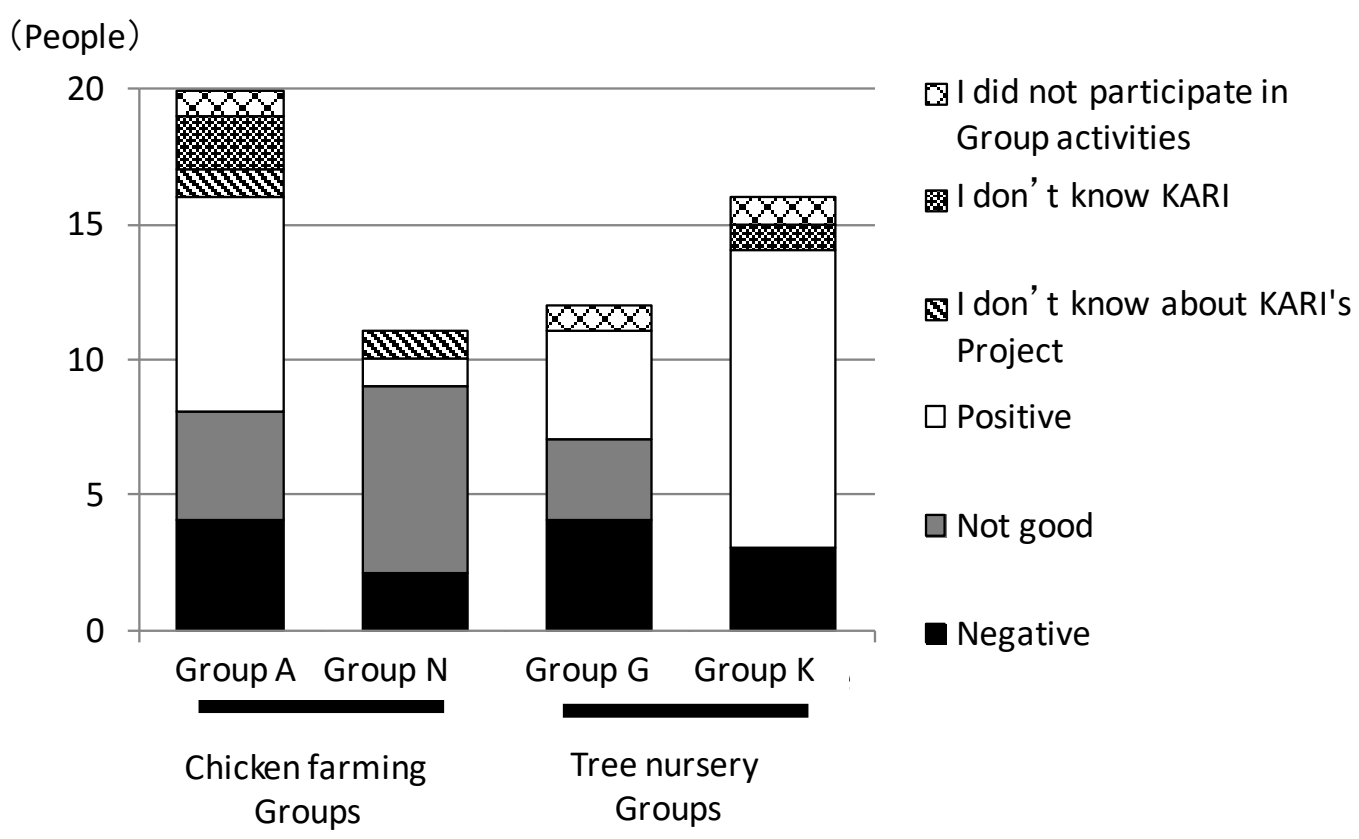

Fig. 6. Evaluations for the KARI's project by the members of 4 CBOs (2011) .

\section{Defining Community}

Before development or research projects begin, the project purpose, target area, amount of funding available, and project period are decided; also, all participants are made aware of their expected roles. After the project has begun, they follow a schedule designed to achieve the common goal. However, many of the aid agencies who started projects in the area under study began their work without a clear understanding of the local people or living conditions there.

Six aid organizations were involved with the environmental rehabilitation project in the area under study. For 20 out of 67 days in 2010 they performed various activities. Due to the visibility of environmental deterioration from the large, expanding gullies many NGO projects were focused on this area. While many aid organizations worked in and visited the area, less than $10 \%$ of the people living there participated in the projects.

As the KARI project was envisioned as participatory in nature, it was important to consider whether the people who live in the target area were aware of the project and how they felt about it. When the project was initiated, the purpose, goal, and duration had already been decided without regard for the local people, this even though these people are the main subjects of the project and their homes its practical base. Once the project was launched, area residents were expected to participate and comply with the given schedule in order to meet the project's goals. Rarely were they provided the opportunity to give feedback on the management of the project. Nor were many deeply involved in the work of the project. Those who did participate often were motivated to by the possibility of more immediate benefits or compensation which could improve their lives.

The surveyed area consisted of two clans of extended families with common paternal ancestry. However, the majority of individuals who participated in development projects were women who had married into the families. So, the most 
involved and visible community participants were not always from the community itself as women accounted for $80 \%$ of CBO members. Fig. 3b shows the distribution of households who had participated in the CBOs that were a part of the KARI project, and had lived near the most serious gully in the area. Most of the people were from the $G$ group. The $G$ group lived in the southwest part of the village near the gully, where they were exposed to dangerous living conditions due to the deterioration of land caused by erosion. This focus area was only a small part of the village. The participants from the $G$ group were motivated by the goal of preventing expansion of soil erosion (Fig. 8). On the other hand, for people who were not seriously affected by the gully, the focus was on their daily issues involving poverty as opposed to environmental restoration.

According our surveys of the area, only three households out of 45 could produce enough food to be self-sufficient (Yamane and Asanuma, 2015). The majority produced only about 3.7 months' worth of food per year. Therefore, many of them had to purchase their food for the remaining eight or so months and were desperate for income. Many people depended on several unstable income sources. In the Rift Valley where the Kipsigis live, the Luo people are often employed in tea plantations with low pay while others ran unstable small businesses. Out of the 45 total households, $19(42 \%)$ did not earn enough money (off-farm income and agricultural income were combined) to provide a maize meal more than once per day. For the people who had not been seriously affected by the gully, the most serious problem was food security.

In the study area, rainfall exceeds $100 \mathrm{~mm}$ per day. During heavy rains, flash floods occur from the direction of the Rift Valley in the gully head and intense water flow aggravates soil erosion in the region. Therefore, in order to prevent the expansion of soil degradation, planting in selected locations or changing the positions of cattle roads is necessary to gain comprehensive control over the flow of water. In areas consisting of paternally extended families with common ancestry, the presence of a consistent traditional authority could not be confirmed. The village chief, assistant chief, and government counsellors were regarded as villagers. However, their residences were located away from the gully and they did not participate in the development projects. In addition, observations during the investigation showed that they were not motivated to play a role in environmental rehabilitation at all unless it involved substantial profit.

\section{CBOs: Reflective of Community?}

Given what appears to be a lack of connection between residents of the area and the development organizations, the author felt it necessary to interrogate the definition of "community" utilized by the KARI project. KARI defined community the way many other aid organizations do - simply classifying all people who lived in the target area as the "community." Therefore, it included local residents other than the CBO members. However, the aid organization did not communicate with non-CBO members. So, although the agency claimed to be working for and with the community, it was actually only interacting with a small segment of it.

To join the CBOs, individuals had to submit a form. In Kenya, the leader who launched the $\mathrm{CBO}$ must register the details of members and activities with a governmental agency called the Ministry of Labour, Social Security and Services. They must also open bank accounts to receive funding. The $\mathrm{CBO}$ has to be registered with social services according to its type. In order for a group to conduct participatory development projects, they must make contact with representatives of the CBOs in the target area. From the viewpoint of the project, regardless of the situations of the active people in CBOs, the important thing is that it is already registered to participate formally 
in a project and satisfies the requirements to be a legitimate participant. Therefore, even if the members and their relationships have changed, if it is registered, the $\mathrm{CBO}$ can participate in the project. The $\mathrm{CBO}$ is defined as a stable thing when, in fact, the community it is meant to represent can be experiencing quite a bit of flux.

If we focus on CBO members that participated in the KARI project, specific members and the names of people were not recorded by the project. Furthermore, only the few members of the CBOs that attended seminars, training, or meetings that were provided by KARI could communicate about the project (Fig. 7).

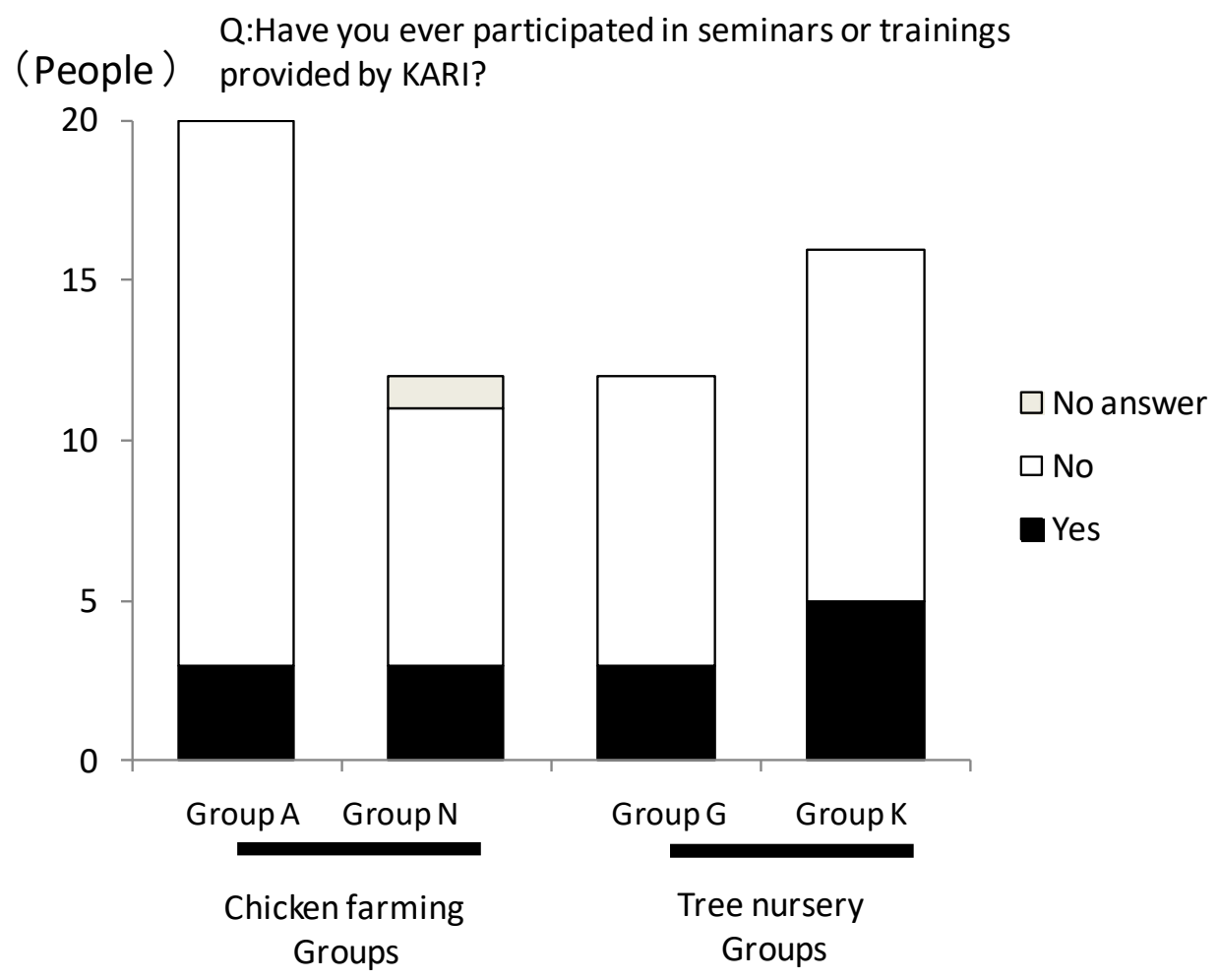

Fig. 7. Members of CBOs of KARIs Project who have attended seminar or trainings during the project (2011).

Activities of the project required that certain members of the CBOs should be sent for training to learn new technologies and gain knowledge. The members that participated in the project were small farmers. Therefore, members were chosen based on their ability to learn the technology or knowledge and to teach it to other members. For example, to speak at a seminar, it was necessary to speak Swahili or English. Some members were women in their 60s or 70s who could understand only the Luo language. This made seminar participation difficult. Even though there were fewer male members, many men participated in the seminars. Importantly, these seminars and lectures were the only time that $\mathrm{CBO}$ members could communicate with the project leaders. Therefore, only particular members were recognised by the project as a "community" and only their remarks were recognised as a true reflection of the activities or opinions of the community. This, even though the daily activities were carried out by CBO members who were not recognised in the project. So, once again, there is a disconnect between the project's definition of community and that of the residents who live in the project area.

Fig. 8 reveals the dalas identified in the study area in the satellite image from April 2009. A total of 541 dalas were confirmed, and among these the dalas of the members of the 4 CBOs participating in the KARI project were identified. These 59 people lived in 32 of the 541 dalas. Therefore, people officially constituting the 
"community" for project purposes made up less than $10 \%$ of the people in the study area. Moreover, the names of members were not recorded and they may have lived anywhere.

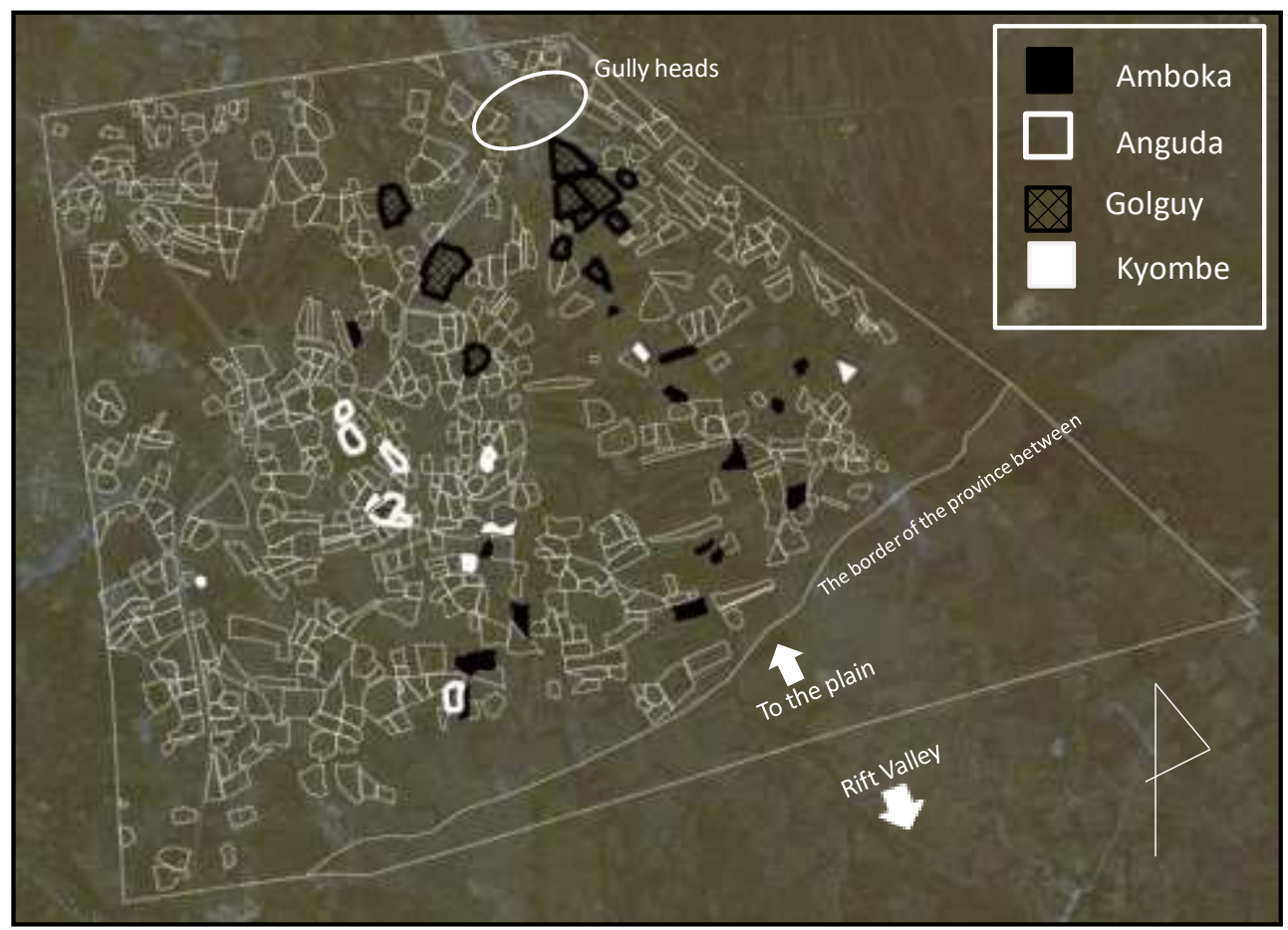

Fig. 8. Distribution of the dalas of the members of 4 CBOs which were participated in KARI's project.

The names of the CBOs that participated in the KARI project were names of the Anyuora that correspond to the lineage of the Luo. The village of Luo consists of dalas who share a common male ancestry (at least this is what people believe). Within the study area, the Jimo-East sublocation consists of two clans: the Jimo clan and the Kasai clan. Names of three of the four CBOs were of Jimo's Anyuora (lineage), and the remaining one was of Kasai's Anyuora. Members' dalas of the A group and the G group were located relatively close to one another and belong to the same Anyuora. Therefore, relatives of the husbands' family lived nearby. However, according to the marriage system of the study area, most women moved into this village from other villages when they got married. Thus, many women who live in the study area did not know each other, except for a few couples from the Jimo clan and the Kasai clan. The women who accounted for many of the $\mathrm{CBO}$ members were unacquainted until they joined the group. Female members of A group who did not know each communicated predominantly through their group leader. Additionally, although the distributions of the dalas of the members of the $\mathrm{K}$ group and $\mathrm{N}$ group were also located relatively close together (Fig. 8), many members of their CBOs belong to different Anyuoras. What does it mean for community-based participatory development projects to be based in communities where members do not know one another well and may not interact?

Although the total number of members of the A group reached around 20, many of them abandoned their activities in 2011 (one year after finishing the project) (Fig. 4). Fig. 9 shows the fluctuation of the number of members in the A group since 2005 . Despite maintaining around ten members from 2005 to 2011, it was found that the individual members had changed (Fig. 9). Their activities included the breeding of improved varieties of chicken, and the selling of chickens and eggs as a source of income. Two people per day took care of and fed the group's chickens. Each person was 
expected to provide labour twice a week. However, according to interviews, most members who stopped attending or abandoned the group activities complained that almost none of the members obtained any compensation for their efforts. Because of this situation and the people's frustration, many members had abandoned their activities in 2009 before the project finished in 2010 (Fig. 9). In order to keep the project running, the leader of the group recruited villagers to keep group numbers up (Fig. 9). This information was not divulged by the leader and a previous member did not know who had abandoned their group activities, calling into question, once again, the definition of community guiding the project. This situation was divulged during the door-to-door visits to the dalas of individual members.

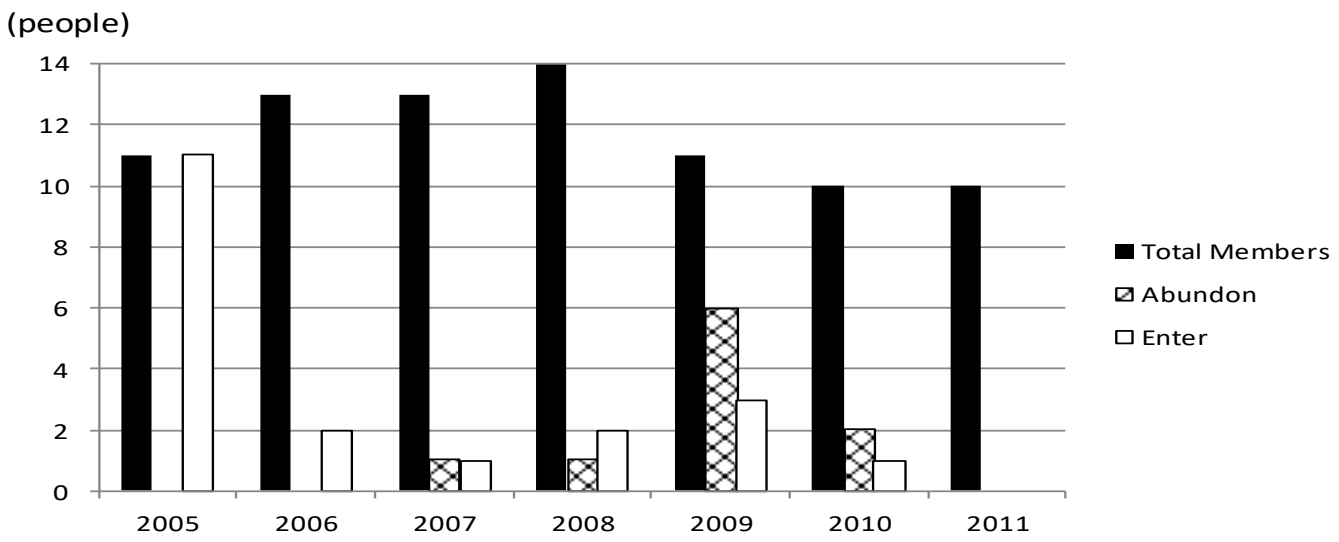

Fig. 9. Fluctuation of number of members of the A Group since 2005.

\section{Discussion}

The complex and dynamic nature of environmental problems requires flexible and transparent decision-making that embraces a diversity of knowledge and values. For this reason, stakeholder participation in environmental decision-making has been increasingly sought and embedded into national and international policy (Reed, 2008). However, with regard to the projects seen in this study, there were situations in which it was hard to say that there was a relationship of trust between the project side and the farmer group participating in it. There did not seem to be one shared understanding of community in the situation nor a real engagement on the part of aid organizations with the people living in the area their project served. How can you create and support participatory development projects if there is no shared understanding?

Project activities focused on seminars and conferences, but in the gatherings hosted by the project CBOs, representatives rarely mentioned specific problems, such as project issues and points for improvement. There was a tendency to make remarks that were thought of as being required, addressing the task imposed by the project side on-the-spot. Also, as remarks were made in English and Swahili, there existed the reality that people who could speak only Luo could not attend, which meant many of the women who participated in the $\mathrm{CBO}$ activities could not interact with the agencies directing the projects. Despite these seminars and lectures being the only way to communicate with the project leaders, only certain community members could participate.

Moreover, while some people participated for the purpose of restoring the environment, many only aimed to improve their lives and income. In addition, the target area was composed of a group of extended family members from the paternal family; the name of the group was given the name of the lineage, sometimes formed by people belonging to the same lineage. Although not always, this means that the traditional social structure had a certain influence on development projects carried out by outside parties. 
Women accounted for more than $80 \%$ of the residents' group members and many of the women living in the area came from outside it and there are many people who are not related and are not even acquaintances (Shiino, 2008). Therefore, in particular, women in Group A often did not know each other and there were also people who lived outside of the village that belonged to the CBOs. People who the aid organization called "community" often turned out to be a collection of unconnected people. In addition, not everyone who was involved participated out of a desire to stop soil erosion. Many people were not directly impacted by the gullies and their motivation for participation was purely for economic reasons. Thus, growing seedlings and planting them was seen more as a source of income than as a way to repair and restore the local environment. Such motivations need to be considered when creating participatory development projects.

The NGO field officers visited the rural areas of their target location frequently. However, the massive size of their area of responsibility was often too large to carry out day-to-day surveys. Therefore, although CBO representatives' name and place of residence were given, it could sometimes be difficult to track down the individual members. In the case of the KARI project, the target area covered a very wide range in two provinces. This, coupled with the fact that the position of project field officer was filled by different people during the project's run, means that the goals and purpose of the project were not always clear to residents. Although necessary supplies and technologies were provided for the CBOs, it was difficult to determine the person most suitable to use them or even whether the technology was something the $\mathrm{CBO}$ could manage at all. Although aid organizations had come frequently to the study area, the relationship between the aid organization and the members of CBOs was superficial. Between them, it seemed that there were walls inhibiting mutual understanding. For representatives of the $\mathrm{CBOs}$, aid organizations were an instrument to obtain benefits; on the other hand, aid organizations need the CBOs to write a report showing achievement. CBO delegates seemed to be doing what they needed to do in order to meet the needs and desires of the aid organizations but were not deeply engaged with the projects themselves.

In the case of efforts to prevent soil erosion caused by gullies in the area, not all residents understood or were aware of the outcomes of the rehabilitation and development activities. That was because not all residents were unsure of, as there was also a lack of understanding of the main objectives of the project. At the same time, it was not always clear who was being referred to as the community - aid organizations, $\mathrm{CBOs}$, and the area residents themselves all seemed to be defining community in different ways. The participation and cooperation of residents living in areas such as Nyando district is essential if aid organizations hope to achieve environmental restoration. The misunderstandings and miscommunications discussed in this article make clear that in order to create and maintain truly participatory development projects, all actors must be involved and aid agencies must understand the cultural contexts in which their projects will be located.

\section{Conclusion}

Many approaches are crucial to lead the success of the development projects. By taking the interests and concerns of multiple stakeholders into account at an early stage, it may be possible to inform project design with a variety of ideas and perspectives; in this way, the livelihood of locals, including their needs and priorities, are successfully met (Stringer et al., 2006). It is argued that participatory processes should lead to higher quality decisions, as they can be based on more complete information, anticipating and ameliorating an unexpected negative outcome before it occurs (Fischer, 2000). But, as 
shown in this research, to be successful projects must truly be participatory in nature; all involved should be informed about the process and goals, should feel free to share honest feedback about how the project is going and what might need to be changed, and should be engaged enough to see the project through to its end. Better understanding of the communities where these projects are located would help domestic and international development groups - better meet the needs of local residents.

It is vital that aid organizations understand the local social structure to some extent, including the cultural perspectives shaping a place, if they want to create effective projects that are also meaningful to the local community. In the case of the environmental restoration projects examined in this article, the goals were ambiguous. Although a major goal was to plant trees in order to prevent erosion, that was not always clear to the area residents. The importance of such work was also not wellcommunicated to a population that struggles to ensure its most basic needs, such as keeping itself fed, are difficult to meet. The concept of resident- and community-based development is important and certainly the goal of environmental restoration is important to the long-term health of the community; however, development projects such as those detailed in this article will remain superficial unless an effective strategy which engages the local residents from the beginning is adopted. In order for participatory, community-based, development projects to be successful members of the communities they mean to serve must be truly engaged in the process.

\section{References}

Cornwall, Andre, 2003. Whose Voices? Whose Choices? Reflections on Gender and Participatory Development. World Development, 31: 1325-1342.

Escobar, Arturo, 2011. Encountering Development: The Making and Unmaking of the Third World. Princeton University Press.

Fair, Jo Ellen and Hehmant Shah, 1997. Continuities and Discontinuities in Communication and Development Research since 1958. The Journal of International Communication, 4 (2): 3-23.

Fische, Frank, 2000. Citizens, Experts, and the Environment: The Politics of Local Knowledge. Duke University Press (North Carolina) p. 351.

Hoshino, Mitsuo, Yusuke Katsurada, Koshi Yamamoto, Hidekazu Yoshida, Mutsuyo Kadohira, Kenichiro Sugitani, John M. Nyangaga, et al. 2004. Gully Erosion in Western Kenya. The Journal of the Geological Society of Japan, 110 (2): 3-4.

Konaka, Shinya, 2006. Anthropology of Dualistic Pastoralist Economy: An Ethnographic Study of Samburu, Kenya [in Japanese]. Kyoto: Sekaishisousya Press.

Mohan, Giles and Kristian Stokke. 2000. Participatory Development and Empowerment: The Dangers of Localism. Third World Quarterly, 21 (2): 247268.

Njuguna, Steven G., 2004. Western Kenya Integrated Ecosystem Management Project (WKIEMP): Environmental and Social Management Framework (ESMF). Nairobi, Kenya: Kenya Agricultural Research Institute. http://www.worldagroforestry.org/economics papers/anonymous/WKIEM $\mathrm{P} /$ Datasets/Louis\%20Verchot/Envi\%20assessment/WKIEMP\%20environ mental $\% 20$ assessment.pdf

Nyasimi, Mary, Lorna Michael Butler, Lee Burras, Hsain Ilahiane, Richard Schultz and Jan Flora, 2007. Differentiating Livelihood Strategies among the Luo and Kipsigis People in Western Kenya. Journal of Ecological Anthropology, 11: 43-57.

Ohama, Yutaka, 2007. Theory and Practice of Participatory Community Development. Creation of New Theoretical Framework and Practical Method [in Japanese]. Okayama: Fukuro Press. 
Quarles von Ufford, Philip, Anata Kumar Giri, and David Mosse, 2003.

"Interventions in Development: Towards a New Moral Understanding of Our Experiences and an Agenda for the Future." In A Moral Critique of

Development: In Search of Global Responsibilities edited by Anita Kumar Giri and Philip Quarles von Ufford, 3-40. London: Routledge.

Reed, Mark S. 2008. Stakeholder Participation for Environmental Management: A Literature Review. Biological Conservation, 141: 2417-2431.

Saito, Fumihiko. 2002. "Development and Participatory: The Emergence of

"Participation" and transition of Development Sense." In Participatory

Development: Towards Development of Poor People Become the Leading Role [in Japanese] edited by F. Saito, 3-26. Tokyo: Nihonhyoronsya.

Shipton, Parker Macdonald, 2007. The Nature of Entrustment: Intimacy, Exchange, and the Sacred in Africa. New Haven: Yale University Press.

Shiino, Wakana (2008). Ethnography of Women in Marriage and Death: Circumstance for

Widows to Choose Men in Luo Society in Kenya [in Japanese]. Kyoto:

Sekaiishisosya Press.

Sigunga, D. O., M. Hoshino, M. J.C. Onyango, S. Asanuma, and M. Kimura., 2011. Pedological Perspective of Gully Erosions Site within Kendu Escarpment-

Sondu Miriu Region, West Kenya. African Journal of Environmental Science and Technology, 5: 1050-1059.

Stringer, Lindsay C., Andrew J. Dougill, Evan Fraser, Klaus Hubacek, Christina Prell and Mark S. Reed 2006 Unpacking "Participation" in the Adaptive Management of Social-ecological Systems: a Critical Review Ecology and Society Vol. 11(2);39. http://www.jstor.org/stable/26266023

Swallow, Brent, 2005. Potential for Poverty Reduction Strategies to Address Community Priorities: Cases of Kenya. World Development, 33: 301-321

World Agroforestry Centre. (2006). Improved Land Management in the Lake Victoria Basin: Final Report on the TransV ic Project (ICRAF Occasional Paper No. 7). Nairobi, Kenya: World Agroforestry Centre.

http://www.worldagroforestry.org/downloads/publications/PDFs/OP1443 $\underline{9 . p d f}$

World Bank, (2010). Implementation Completion and Report (TF-054250) on a Grant in the Amount of US\$4.1 Million to the Republic of Kenya for a Western Kenya Integrated Ecosystem Management Project.

http://documents.worldbank.org/curated/en/744731468044993792/text/IC $\underline{\text { R15330P0729810311511110BOX358315B.txt }}$

Yamane, Yuko and Shuichi Asanuma, 2015. Economic and Socio-Cultural Evaluation of Livestock Farming Amid Severe Soil Degradation in Western Kenya. African Journal of Agricultural Economics and Rural Development, 3 (7): 253265. 